\title{
DER BEITRAG DER GEOGRAPHIE ZU RAUMFORSCHUNG UND RAUMORDNUNG
}

\author{
Klaus Wolf \\ PRISPEVEK GEOGRAFIJE K POKRAJINSKEMU VREDNOTENJU IN PROSTORSKEMU \\ NAČRTOVANJU
}

Izvleček

UDK $911.711=30$

Prispevek obravnava pomen sodobne socialne geografije za pokrajinsko vrednotenje in prostorsko načrtovanje. Izpostavljen je geografski pristop v trikotniku: opis - razlaga uporaba.

Ključne besede: Socialna geografija, uporabna geografija, prostorsko načrtovanje

\section{A CONTRIBUTION OF GEOGRAPHY TO THE LANDSCAPE EVALUATION AND SPACE ORDERING}

\section{Abstract}

The paper discusses the significance of contemporary social geography for the landscape evalution and space ordering. Exposed is the geographical approach in triangle: descriptionexplanation-application.

Key words: Social geography, Applied geography, Space ordering.

\footnotetext{
* Dr., prof., Institut für Kulturgeographie, Stadt - und Regionalforschung, Johann Wolfgang
} Goethe - Universität, Senckenberganlage 36, D-60325 Frankfurt am Main, Deutschland. 
Vladimir Klemenčič gehört zu der Generation von Geographen in Europa, die die Bedeutung der Geographie, vor allem der Human-Geographie, für die zukünftige Ordnung des Raumes nicht nur erkannt haben, sondern ihre Forschung in konsequenter Verfolgung dieser Erkenntnis auf die Bearbeitung von Fragen ausrichteten, die ,anwendungsorientiert“ sind.

Etwa um das Jahr 1970, damals noch Assistent, kam ich zum ersten Mal nach Ljubljana und konnte die Gedankengänge Klemenčič, sei es zu Fragen der Agrar- und Siedlungsgeographie, der Bevölkerungsgeographie, vor allem zu Fragen der Ethnischen Minderheiten, kennenlernen - immer wieder fielen mir die anwendungsorientierten Fragestellungen auf und haben meine eigenen Arbeiten auf den Gebieten der Stadtgeographie, der geographischen Erforschung der Freizeit und des Tourismus, besonders auch zur Entwicklung von Agglomerationen angeregt. Gerade die wissenschaftlichen Diskussionen auf gemeinsamen Seminaren, Symposien oder Kolloquien, die besonders auch durch meine intensive Kooperation mit Klemenčič's Schüler Mirko Pak gefördert wurden, haben zu intensiven wechselseitigen Anregungen geführt.

Vor dem Hintergrund dieser Diskussion will ich versuchen, aus meiner Sicht zu formulieren, worin ich den Beitrag einer modernen (Human-) Geographie zur Raumforschung und Raumordnung sehe.

Wenn die moderne Humangeographie Handlungen der Menschen auf der Erdoberfläche in ihrer Verbreitung, ihrer Durchführung und in ihren ,erdräumlichen“ Konsequenzen (materielle Artefakte) zum Gegenstand hat, sind daraus für die konkrete wissenschaftliche Bearbeitung eine Reihe von Fragen abzuleiten:

- was ist unter ,geographisch“" relevantem Handeln zu verstehen,

- ist dieses Handeln ,nur“ zu beschreiben, auch zu erklären, oder gar konzeptionelzu bewerten, d.h. auf ein bestimmtes Ziel hin zu formulieren?

- sind demnach daraus auch Leitziele und Maßnahmen für „,erdräumliches“ Handeln abzuleiten.

Bevor ich zur Ableitung "des Beitrags für Raumforschung und Raumordnung" komme, will ich versuchen, die gestellten Fragen in aller Kürze zu beantworten:

Handlungsorientierte Geographie geht dabei über bisherige Ansätze hinaus. Nicht die Artefakte abgeschlossener Handlungen des Menschen stehen im Vordergrund der Analyse, sondern Handeln, auch soziales Handeln, wird verstanden als menschliches Verhalten, das mit einem subjektiven Sinn verbunden ist und sich an sozialen Normen und Werten orientiert - insoweit folgt diese Auffassung Max WEBER (vgl. MESSING u. HENNEN 1989, 264 ff.)., „Geographisches Handeln“ bedeutet dabei das sinngerichtete Verhalten, das räumliche Strukturen in das Handeln einbezieht, ob explizit oder implizit, im Grunde hat damit jedes Handeln eine geographische Komponente. $\mathrm{Ob}$ der Mensch wirtschaftlichen Tätigkeiten nachgeht, sich um seine Wohnung kümmert, seine Freizeit verbringt, immer trifft er Entscheidungen, die 
bestimmte Flächen der Erdoberfläche, bestimmte Standorte im Sinne der Bewertung für sein sinnhaftes Handeln auf ein intendiertes Ziel hin bewerten. Dabei richtet er sich nach bestimmten Normen und Werten. Diese können durch staatliche Gewalt, andere Machtfaktoren vorgegeben sein, es können aber auch ethische Werte wie Solidarität, Toleranz, Sozialbindung das Handeln bestimmen.

Ein erster wichtiger Schritt einer handlungsorientierten Geographie ist nun sicher, dieses raumbezogene-geographische Handeln zu beschreiben. Beschreiben heißt dabei häufig, erst einmal bewußt zu machen, daß viele oder sogar die meisten menschlichen Handlungen in ihren räumlichen Implikationen nicht ,mitgedacht" werden und die räumlichen Folgen leider auch außer acht gelassen werden.

Schon in der Verdeutlichung dieser Raumbezüge kann ein wichtiger Beitrag der handlungsorientierten Geographie zur Raumforschung und Raumordnung bestehen.

Sie muß aber auch noch weitere Schritte gehen, hin zur Erklärung und zu konzeptionellen Ansätzen.

Schon die Erklärung sinnhaften Handelns in seinen "geographischen“ Implikationen bereitet methodische Probleme der Bearbeitung. Es kann nicht mehr mit „Zählen“, „Kartieren“, auch kaum noch mit standardisierten Befragungen gearbeitet werden; denn es sollen ja Zusammenhänge aufgezeigt werden, warum, d.h. mit welcher Intention der oder die Handelnden welche Handlungen vollzogen haben oder, was im Sinne einer anwendungsorientierten Raumforschung und Raumordnung noch wichtiger erscheint, mit welchen Intentionen Handlungen vorbereitet werden. Für die Erklärung kommen nun weitgehend nur sogenannte hermeneutische Verfahren in Betracht, die Sinnzusammenhänge verstehend interpretieren. Sie gleichen manchmal kriminalistischer Kombination und bedienen sich vom Quellenstudium, z.B. aktueller Quellen wie Berichten in Zeitungen und Rundfunk und Fernsehen, bis hin zu intensiven problemorientierten Gesprächen mit den sog. Handlungsträgern, die interpretierend verarbeitet werden. So kann versucht werden, die mit bestimmten Absichten verbundenen Handlungen in ihrem Handlungsverlauf und in ihren Ergebnissen zu erklären. Häufig kann so nachgewiesen werden, daß z.B. auch und gerade raumrelevantes Handeln sog. „Aushandlungsprozessen“ verschiedener Interessengruppen, die nach Interessenausgleich, nach Kompromissen streben, entspringt und daher häufig von einer rein rationalen optimaleren Entscheidung weit entfernt ist.

Das „Erklären“ dieser Zusammenhänge könnte man auch als evaluatives Verfahren zur Bewertung abgelaufener raumrelevanter Prozesse bezeichnen, aus dem zumindest Erkenntnisse gewonnen werden können, wie möglicherweise bei ähnlich gelagerten Interessen ähnliche „Aushandlungsprozesse“ zu ähnlichen, wenig raumverträglichen Ergebnissen kommen. 
Diese „evaluativen“ Erklärungen sind auch ein guter Grundstein für die zielorientierte konzeptionelle Bewertung. Dabei ist allerdings unausweichlich, daß konzeptionelle Äußerungen selbst wieder an Leitbildern, Werten orientiert sein sollten, d.h. anwendungsbezogene handlungsorientierte Geographie unterscheidet sich explizit insoweit von herkömmlichen Ansätzen, als sie ihre Leitbilder und Wertekategorien offenlegen muß. Nur wenn sie dazu bereit ist, kann sie einen Beitrag zu Raumforschung und Raumordnung leisten.

Was verstehen wir unter Raumforschung und Raumordnung?

Zweifellos ist die Raumforschung eine fächerübergreifende Disziplin, deren Gegenstand, Methoden, Verfahren und Arbeitsweisen interessanterweise auch in jüngeren (deutschsprachigen) Nachschlagewerken häufig nur relativ kurz und allgemein definiert wird. Während in der 8. Auflage des DIERCKE Wörterbuch der Allgemeinen Geographie $(1995,125)$ nur gesagt wird: „1. Allgemein Erforschung des Raumes durch Geo- und Biowissenschaften, vor allem die Geographie, sowie verschiedene Praxisbereiche“ und ,2. heute wird Raumforschung überwiegend bezogen auf die Raumordnung, innerhalb derer die Raumforschung als Methode zur Bestimmung der Bedingungen des Lebensraumes für dessen Weiterentwicklung durch die Raumplanung bzw. Raumordnung" gilt, dann zeigt dies doch eine zu oberflächliche Auseinandersetzung mit dem Begriff der Raumforschung, vor allem auch hinsichtlich der zu pauschalen Heraushebung der Geo- und Biowissenschaften, so daß dadurch gerade im Konzert der raumforschungsrelevanten Disziplinen der Geographie ein schlechter Dienst erwiesen werden könnte.

Im Sinne einer gerecht gewichtetenden Bewertung des Beitrags der Geographie zur Raumforschung und Raumordnung viel hilfreicher ist hier die Auffassung LENDI's $(1995,627)$ im Handwörterbuch der Raumordnung der Akademie für Raumforschung und Landesplanung: „Die Ermittlung des Ist-Zustandes wie auch der trendmäßigen räumlichen Entwicklung ist eine Aufgabe der Raumforschung. Sie hat zu bestimmen, nach welchen Kriterien der Ist-Zustand des Raumes zu beschreiben und zu verstehen ist. Ebenso gehört zu ihren Aufgaben, die räumlichen Entwicklungskräfte zu erfassen und die räumlichen Veränderungen vor dem Hintergrund des Ist-Zustandes sowie der prozeßhaften raumverändernden Faktoren zu prognostizieren und also die trendmäßige räumliche Entwicklung darzustellen.“

Im Forschungsdesign der Raumforschung ist also das Normative, die auf zukünftige Entwicklung ausgerichtete Setzung angelegt - alle Fragestellungen der Forschung stehen unter dem Leitbild der Handlungsorientierung und beziehen sich auf den Raum - wobei im Rahmen dieses Beitrags eine weitergehende Exegese über den Raum unterbleiben soll. Insoweit wird zweierlei deutlich, daß je nach Setzung bestimmter Leitbilder ganz unterschiedliche Disziplinen an der Raumforschung - von den Wirtschafts- und Sozialwissenschaften, und darunter auch die Humangeographie -, bis 
hin zu naturwissenschaftlichen Disziplinen zu beteiligen sind und daß nur eine handlungsorientierte (Human-) Geographie im eingangs beschriebenen Sinn einen wirklichen Beitrag zur Raumforschung leisten kann. Solange Geographie nicht in dem Dreiklang : Beschreibung - Erklärung - Entwicklung konzeptioneller Soll-Zustände raumbezogenen Handelns angesiedelt ist, kann sie zu einer wissenschaftlich betriebenen Raumforschung nichts beitragen. Daß es schon seit geraumer Zeit andere Ansätze im Sinne dieser Abhandlung gibt, zeigen z.B. die wissenschaftlichen Beiträge Vladimir Klemencic's.

Bleibt noch zu klären, wie sich Raumforschung und Raumordnung aufeinander beziehen.

Einmal wird der Begriff Raumordnung im Grundgesetz der Bundesrepublik Deutschland in Artikel 75, Nr. 4 benutzt, indem dem Bund das Recht eingeräumt wird, eine Rahmengesetzgebung für die Raumordnung zu erlassen, erläutert oder bestimmt wird der Begriff aber nicht.

Heute wird der Begriff in unterschiedlicher Bedeutung gebraucht:

- als tatsächliche räumliche Struktur eines Gebietes,

- als eine leitbildgerechte Ordnung des Raumes oder

- als die Tätigkeit, durch die eine angestrebte räumliche Ordnung verwirklicht werden soll/(ERNST 1995, 752).

Raumordnung ist also weitgehend die normative Komponente zur zukünftigen Ordnung des Raumes und der Findungs- und Durchsetzungsprozeß für die Implementierung dieser angestrebten räumlichen Ordnung.

Mit LENDI (1995, 627) kann nun zweifelsfrei angenommen werden, daß Raumordnung im gerade beschriebenen Sinn aus den Forschungserkenntnissen, so sie konzeptionell, leitbildorientiert ausgerichtet sind, der Raumforschung hervorgehen. Ihre Implementierung unterliegt dem politischen Willensbildungs- und Durchsetzungsproze $ß$. Daher ist auch zu verstehen, daß Vertreter raumforschungsorientierter Disziplinen nicht selten wenig zufrieden sind mit dem aus „, ihren Forschungserkenntnissen“ abgeleiteten raumordnungspolitischen Setzungen zwischen substantieller wissenschaftlicher Erkenntnis und raumordnungspolitischer Handhabung besteht eben keine geradlinige Ableitung! 
Zusammengefaßt können wir feststellen:

- handlungsorientierte, an Werten und Normen ausgerichtete, auf den Raum bezogene, konzeptionell-normativ arbeitende (Human-) Geographie ist in hohem Maße eine bedeutende Teildisziplin der interdisziplinären Raumforschung.

- Je nach Zielsetzung entwickelt sie Fragestellungen, beschreibt, erklärt raumbezogenes Handeln und liefert konzeptionelle Szenarien zukünftiger Sollzustände, weitgehend auch und gerade mit der Vermittlung geeigneter Maßnahmen zur Implementierung.

- Handlungsorientierte (Human-)Geographie leistet so nicht nur einen essentiellen Beitrag zur Raumforschung, sondern auch zu dem Prozeß der der politischen Willensbildung unterworfenen Raumordnung.

\section{Literatur}

- Diercke Wörterbuch der Allgemeinen Geographie. Band 2. N-Z (hrsg. v. H. Leser u.a.) München, 1995.

- Ernst W., 1995: Raumordnung. In: Handwörterbuch der Raumordnung, hrsg. v.d. Akademie für Raumforschung und Landesplanung, 752-758. Hannover.

- Hennen M., 1989: Handlungstheorie. In: Wörterbuch der Soziologie, Bd. 1, 266271. Stuttgart.

- Lendi M., 1995: Leitbild der räumlichen Entwicklung. In: Handwörterbuch der Raumordnung, hrsg. v.d. Akademie für Raumforschung u. Landesplanung, 624629. Hannover.

- Messing M., 1989: Soziales Handeln. In: Wörterbuch der Soziologie, Bd. 1, 264266. Stuttgart.

- Weber M., 1984: Soziologische Grundbegriffe, 6. Aufl., Tübingen. 


\section{PRISPEVEK GEOGRAFIJE K POKRAJINSKEMU VREDNOTENJU IN PROSTORSKEMU NAČRTOVANJU}

\section{Povzetek $^{1}$}

Geografija si je pogosto zastavljala vprašanja o pravem, geografsko relevantnem raziskovanju. Pri tem je poizkušala razjasniti dilemo v koliko naj pojave in procese "le" opisuje, oziroma do kod jih "sme" še razlagati. Sodobna geografija se dandanes sooča še z večjo skušnjavo: ali sme določen problem ovrednotiti tako, da bo ustrezal opredeljenim koncepcijskim predpostavkam in bo znanstvena obravnava vodila $\mathrm{k}$ povsem določenim ciljem? Prispevek je, skladno z nakazanim izhodiščem, v celoti posvečen "geografskemu ukrepanju" ("geographisches Handeln") oziroma aplikaciji geografskega raziskovanja.

Geografija izhaja iz registracije zapaženega in opisovanja prostorskih procesov. Obojno videno kot učinek oziroma rezultat $v$ pokrajinski stvarnosti. Sodobni raziskovalec pa spoznava, da prostorska stvarnost ni le izključno stvar množice (pojavov, učinkov, ... ) in medsebojnih prepletanj temveč, da je končni rezultat (človekovega) dełovanja $\vee$ prostoru (lahko) povsem iracionalne narave. Zastavlja se vprašanje pod kakšnimi pogoji se je sprožil proces, kateri intenciji je sledil in katerim kompromisnim rešitvam je podlegel? Geograf $\mathrm{s}$ tradicionalnim raziskovalnim aparatom ne zna oziroma ne zmore razložiti omenjene kompleksne povezave. Kartiranje in seštevanje iz statistike in ankete pridobljenih števil mu pri tem nič ne pomaga. Tudi soočanje problemskih vsebin (na karti s prekrivanjem, ali v empirični korelaciji) je poprej balast kot razlaga obstoječega. Kako naj torej ukrepa?

V kolikor želi biti verodostojen mora priznati, da izhaja iz povsem predvidljivih modelov oziroma koncepcijskih predpostavk. Sebi mora najprej odgovoriti na vprašanje kako umeva geografske raziskave (Raumforschung) in kako opredeljuje prostorsko urejanje (Raumordnung). LENDI $(1995,627) \mathrm{v}$ svojem priročniku za prostorske načrtovalce trdi, da je "ugotavljanje zatečenega stanja (der Ist-Zustand), kot tudi z njim povezanih prostorskih procesov, naloga geografskih raziskav, ki naj upoštevajo lastne, problemu aplicirane kriterije ... " Izhajajoč iz povedanega ugotavljamo, da geografijo lahko vidimo le v dopolnjujočem trikotniku “opisovanje razlaga - aplikacija". V kolikor ne predvidi koncepta zaradi česar deluje, v kolikor torej ne opredeli "naj stanja"/der Soll - Zustand/ ne služi znanosti, še najmanj pa prostorskim načrtovalcem. Jubilant se je tega dobro zavedal.

Prostorsko urejanje (Raumordnung) pojmujemo v sodobnosti kot normativni člen dokončne urejenosti krajine. Zato je potrebno, da si že $v$ tej fazi razjasnimo dvoje:

\footnotetext{
'Pripravil in prevedel dr. Anton Gosar
} 
prvič, izhodišče (kje smo); ter drugič, uveljavljanje oziroma implementacijo (kaj želimo) - skladno z družbeno-politično koncepcijo razvoja. Dejanska implementacija je posledično, navkjub vsemu, izraz politične volje in zmožnosti. V kolikor našega, izhodiščno-ciljnega geografskega stališča ni, so (lahko) naša dejanja - raziskave le samemu sebi namen.

V skladju z gornjim razmišljanjem lahko izpeljemo naslednje zaključke:

- aplikativna, vrednostno in normativno ter konceptualno/ciljno opredeljena družbena geografija (Human-Geographie) je pomembna znanstveno-raziskovalna veja $v$ interdiciplinarnem proučevanju prostora;

- po gornji definiciji opredeljena stroka odstira probleme, opisuje in opredeljuje prostorske procese ter, nenazadnje, posreduje scenarije razvoja, $v$ smeri t. i. najstanja;

- aplikativna družbena geografija s takim delovanjem ne bogati le vedo oziroma prostorsko načrtovanje (Raumordnung), temveč odločilno sooblikuje proces političnega odločanja in temu podrejenega regionalno-prostorskega planiranja. 